\title{
O desenvolvimento histórico da administração e a gestão do ensino superior
}

\author{
Rafael Castro Rabelo*
}

\begin{abstract}
Resumo
Este artigo parte do pressuposto de que o trabalho humano, que se realiza numa instituição escolar de ensino superior, tem como um dos elementos essenciais a gestão. A questão que norteou a pesquisa foi: qual a influência das diferentes escolas de gestão sobre a administração das instituições de ensino superior brasileiro público e privado? A relevância de se investigar esta questão evidencia-se pela contribuição que traz para a compreensão da gestão universitária na atualidade, seus elementos e suas contradições. Nesse sentido, optou-se pela pesquisa bibliográfica, cujo objetivo geral foi descrever a gênese da administração como campo de conhecimento e de práticas voltadas para as organizações. Com este propósito, selecionei, entre outras, obras de dois autores da área da administração de empresas no Brasil: Idalberto Chiavenato e Reinaldo Oliveira da Silva. Primeiramente, procuro mostrar como ocorreu o desenvolvimento da administração na sociedade, particularmente nas organizações, para, em seguida, considerar a importância dessa administração no campo da educação, em especial no âmbito da gestão na universidade.
\end{abstract}

Palavras-chave: Gestão na universidade; Desenvolvimento histórico da administração; Gestão burocrática.

\section{Introdução}

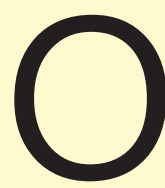

tema deste trabalho é a gestão no ensino superior, num recorte que delimita o âmbito da universidade. Hoje, no Brasil, é possível constatar uma intensificação das preocupações e debates acerca da universidade e de seu futuro, principalmente a universidade pública, considerando-se a necessidade de mudanças na forma de organização. A partir do Estatuto de 1931, as universidades públicas tiveram que se enquadrar aos padrões determinados pelo Governo Federal, mantendo suas estruturas, uma vez que estavam envolvidas pelas forças de interesses políticos e burocráticos.

Cunha (1999) faz referência ao panorama do campo universitário descrito por Clark chamando a atenção para a crença de que qualquer organização deve ter unidade de comando, realizar suas escolhas racionais entre o conjunto de alternativas e estabelecer 
prioridades de execução. Entretanto, na universidade o monopólio do poder representa uma série de ameaças para essa organização, que reúne colaboradores especializados em diversas áreas. Para clarificar essa situação, Clark utiliza a metáfora da universidade como uma anarquia organizada nas Instituições de Ensino Superior (IES).

Coma reformauniversitária de 1968, foi possível verificara aplicação, nas IES, da concepção de organização da produção fabril instituída por Taylor em Organização Racional do Trabalho que estava expressa em duas diretrizes: 1) eliminação da duplicação de meios para fins idênticos ou equivalentes; 2 ) separação entre as atividades de concepção e execução. Essas diretrizes encontram-se na estrutura e funcionamento da maioria das instituições universitárias brasileiras até os dias de hoje, como se constata no regime departamental e divisão dos cursos de graduação.

A departamentalização redundou na criação de uma nova instância na organização das universidades - a coordenação e o colegiado de curso. Complementando a departamentalização e a divisão dos cursos de graduação, surge o regime de créditos. Toda essa dinâmica resultou, assim, na racionalização da produção das universidades federais no Brasil.

Assim como o ensino público, o ensino superior privado, que compõe $89 \%$ das IES no Brasil, segundo dados do MEC 2007, passou pelas mesmas transformações citadas anteriormente, porém com uma preocupação ainda maior nos dias atuais, pois, para sobreviver em um mercado altamente competitivo, trata a academia como negócio, o ensino como produto, praticando a gestão estratégica de negócios.

Machado (2008), afirma que são diversos os problemas verificados nas IES privadas. Entre eles destacam-se dificuldades financeiras, falta de posicionamento mercadológico, dificuldade em ocupar as vagas oferecidas no vestibular, falta de fidelização dos discentes, falta de medição de desempenho, distância do mercado empregador, falta de pesquisa, insatisfação interna etc. Segundo o autor, esses fatores estão ligados a dois problemas centrais: a falta de um modelo de gestão definido e a falta de gestores competentes.

Atuar na área educacional exige unir o trabalho com conhecimento científico (ensino e aprendizagem) às práticas de gestão voltadas à formação do indivíduo para a transformação social. Na universidade, essa união adquire contornos próprios por envolver também a pesquisa 
O desenvolvimento histórico da administração e a gestão do ensino superior

e a extensão, tornando ainda mais relevantes as relações entre práticas de gestão e trabalho educativo e pedagógico. Porém, em geral, os métodos de gestão que se encontram nas universidades no Brasil, são aqueles que se caracterizam mais fortemente pela semelhança com os métodos da produção fabril, com foco na racionalização da produção, numa posição contrária aos interesses educativos e pedagógicos de formação do indivíduo para a transformação social.

\section{Administração pré-moderna}

A atividade administrativa tem evolução científica recente na história da humanidade, mas sempre esteve presente como atividade prática considerada arte e realizada em qualquer tipo classe e tamanho de organização. Silva (2001) mostra que a administração é uma atividade encontrada em empreendimentos de qualquer espécie, de todos os povos, em todos os tempos históricos. O autor observa que os grandes líderes na história da humanidade foram administradores, administrando países, coordenando explorações, dirigindo guerras, gerindo os esforços de outros homens.

A importância da administração para impulsionar o crescimento das nações é inegável, mas sua reconstituição histórica não é tarefa fácil porque os registros, quando existem, são confusos e remotos.

Acredita-se que a administração está ligada a civilizações muito antigas, iniciando-se na Suméria, por volta de 5000 anos atrás, onde foram encontrados os documentos escritos mais antigos que tinham como finalidade registrar o controle administrativo. A partir do momento que os sumérios buscavam melhorar a forma de solucionar seus problemas práticos, começaram a exercer a arte de administrar.

Os sacerdotes sumérios arrecadavam e administravam grandes volumes de bens e valores. Esses sacerdotes prestavam contas de sua administração ao sumo sacerdote o qual realizava uma prática que se configurava como fiscalização administrativa. Tais práticas tiveram significativa importância sendo que "o desenvolvimento sumério foi seguido de perto pela ascensão do Egito, com suas estruturas arquitetônicas, seus escritos e seu governo,

Revista @rquivo Brasileiro de Educaçao, Belo Horizonte, vol.2, num.3. jan-jul. 2014. 
no que se refere à evolução administrativa" (SILVA, 2001, p.87).

No Egito, a construção da pirâmide de Quéops durou cerca de 20 anos, envolvendo mais de cem mil trabalhadores. A união dos esforços desses trabalhadores demandou ações administrativas para que atingissem os objetivos propostos. Também era necessário gerir e solucionar problemas como transporte e alojamento para os trabalhadores. Fica claro que, nessa época, já se realizavam práticas administrativas como planejamento, organização, direção e controle.

Na Babilônia, também se verifica a presença de muitas práticas administrativas, por exemplo, quando se estabeleceu o "Código de Hamurabi", uma representação de um pensamento administrativo que vigorou de 2000 a 1700 a.C. Esse código foi uma estratégia desenvolvida para se atingir o objetivo de fazer com que as cidades se unissem, mantendo a paz e estabelecendo uma legislação.

No reinado de Hamurabi, rei da Babilônia, as cidades ao longo do vale foram obrigadas a se unir para manter a paz e estabelecer uma legislação para abranger a propriedade pessoal, rural, o comércio, os negócios, a família e o trabalho. Estas leis vieram a se chamar 'Código de Hamurabi' (SILVA, 2001, p. 88).

Também entre os chineses, há mais de três mil anos, já havia a noção de algumas práticas administrativas como as mencionadas, quais sejam: planejamento, direção, organização e controle. Como relata Silva (2001), estavam presentes entre eles conceitos administrativos que se assemelham ao tom administrativo contemporâneo de organização, cooperação, funções, procedimentos visando à eficiência, além de várias técnicas de controle.

$\mathrm{Na}$ Grécia, uma grande manifestação na arte de administrar é verificada com a criação da administração democrática de um governo, o que deu início ao método científico. Os gregos perceberam a implantação de métodos uniformes aliada ao ritmo estipulado garante a produção máxima (SILVA, 2001). Esse princípio se explicita claramente nos estudos de Frederick W. Taylor, Frank B. Gilbreth, Henri Fayol, entre outros estudiosos das teorias administrativas.

Em Roma, ao se juntarem novos povos e territórios, houve grande necessidade de se organizar e controlar de forma mais eficiente todo seu império. Nesse contexto, as práticas de administração tiveram

Revista @rquivo Brasileiro de Educaçao, Belo Horizonte, vol.2, num.3. jan-jul. 2014. 
O desenvolvimento histórico da administração e a gestão do ensino superior

grande avanço no sentido da aprendizagem com os erros e acertos. Há que se destacar que foi em Roma que ocorreu a primeira experiência mundial de organização de um império verdadeiramente grande.

A Igreja Católica, considerada a organização formal mais eficiente e antiga da civilização ocidental, foi uma herança do Império Romano. Sua eficiência estava ligada a questões organizacionais importantes em função das novas doutrinas que surgiam e da disseminação da crença cristã. Seus dirigentes perceberam a importância de se estabelecer, com mais critérios os objetivos, as doutrinas e a conduta das atividades cristãs com suas normas e regras. A consequência disso foi uma grande organização religiosa com centralização de poder, sob a responsabilidade do papa. Durante séculos, a Igreja exerceu sua força de atração de objetivos. A eficácia de suas técnicas organizacionais e administrativas espalhou-se pelo mundo influenciando o comportamento das pessoas.

Assim como a Igreja católica romana, as organizações militares também se destacaram na evolução histórica da administração. Evoluíram das displicentes ordens dos cavaleiros medievais e dos exércitos mercenários dos séculos XVII e XVIII até os tempos modernos com uma hierarquia de poder rígida e a adoção de princípios e práticas administrativas que ainda se verificam em empresas da atualidade, tais como: a unidade de comando, que estabelece que cada subordinado só pode ter um superior; princípios de organização, planejamento e controle centralizados em paralelo com operações descentralizadas; e princípio de direção. Todas essas diretrizes, desenvolvidas na organização militar romana, contribuíram para o surgimento das teorias administrativas.

O desenvolvimento tecnológico despontava e se aprimorava cada vez mais. A partir do momento em que as pessoas evoluíam em seus meios de trabalho, como arar o solo, produzir armas e tecer, inevitavelmente acontecia a evolução tecnológica. Porém, o marco principal desse avanço foi a Revolução Industrial, ocorrida na Inglaterra, que consistiu um conjunto de mudanças com grande impacto no processo de produção influenciando os aspectos econômico e social.

No final do século XVIII e início do século XIX, o fenômeno da Revolução Industrial trouxe rápidas e profundas mudanças econômicas, sociais e políticas, causando o surgimento da empresa e da moderna administração. A base dessa revolução foi a substituição

Revista @rquivo Brasileiro de Educaçao, Belo Horizonte, vol.2, num.3. jan-jul. 2014. 
da mão de obra humana pelo trabalho da máquina, gerando transformações drásticas na vida das pessoas e das empresas.

Como núcleo da Revolução Industrial, surgiu o motor a vapor que passou a fornecer uma energia mais barata e eficiente, revolucionando a indústria e o comércio. Tal revolução decorreu do fato de que essa nova fonte de energia reduziu significativamente os custos de produção e, consequentemente, os preços dos produtos, levando à ampliação dos mercados. Devido a isso, as indústrias evidenciaram a necessidade maior de administração e organização, considerando-se também que a expansão dos mercados requeria mais trabalhadores, maior número de máquinas e um nível maior de produção para manter resultados positivos constantes.

A máquina a vapor, criada por James Watt (1736-1819), provocou grande transformação na formulação do trabalho e modificou a estrutura social e comercial, com reflexos na política e na economia.

A Revolução Industrial passou por duas fases. A primeira, entre 1780 até meados de 1860, teve o carvão como a principal fonte de energia e o ferro como principal matéria-prima ${ }^{1}$. A segunda fase da Revolução Industrial, ${ }^{2}$ que corresponde ao período de 1860 a 1914, foi marcada pelas transformações resultantes do uso da eletricidade e derivados do petróleo como novas fontes de energia e do aço como a nova matéria-prima. Nesse contexto, origina-se a moderna administração como resposta às novas necessidades que apareceram em decorrência de alguns fatores principais: 1) crescimento acelerado e desorganizado das empresas, passando a exigir uma administração científica capaz de substituir o empirismo e a improvisação; 2) necessidade de maior eficiência e produtividade das empresas para responder à intensa concorrência e competição no mercado. Estavam, assim, dadas as necessidades e condições históricas para o surgimento da administração científica.
1 Nessa primeira fase, a Revolução industrial se desenvolveu em quatro etapas: 1) mecanização da indústria devido à criação das máquinas de fiar, tear hidráulico e mecânico e da agricultura que substituíram a força do trabalho humano e animal; 2) aplicação da força motriz à indústria, utilizando o vapor nas máquinas industriais, transformando as oficinas em fábricas; 3) desenvolvimento do sistema fabril, provocando o fim da atividade do artesão com sua oficina, que cedeu espaço para as fábricas e operários; 4) espetacular aceleramento dos transportes e das comunicações como a navegação a vapor, as hélices, a primeira estrada de ferro, o telégrafo elétrico, o selo postal e o telefone

2 Nessa segunda fase, acontece a segunda Revolução Industrial causada pelo processo de fabricação do aço, aperfeiçoamento do dínamo e invenção do motor de combustão interna.

\subsection{A administração científica e a organização da escola: divisão, hierarquização, padronização}

A descrição apresentada anteriormente teve o objetivo de mostrar, de forma abreviada, que o desenvolvimento da administração ao longo de séculos foi marcado por distintos 
O desenvolvimento histórico da administração e a gestão do ensino superior

aspectos e sempre em função das necessidades organizacionais de cada época. Passo agora a descrever de que forma surgiram as principais teorias administrativas, em que contexto e como evoluíram, buscando especificar as particularidades de cada corrente teórica.

A primeira teoria da administração foi formulada pelo engenheiro Frederick Taylor (1856-1915), americano nascido na Pensilvânia, descendente da família Quaker. Ele recebeu uma educação rigorosa e disciplinada, adquirindo conhecimentos das línguas francesa e alemã. Iniciou seu aprendizado como operário em uma pequena metalúrgica e, após alguns anos de trabalho nessa empresa, buscou melhorias em sua vida profissional atuando também em outras empresas, de operário, passou a engenheiro. Ao desenvolver a Teoria da Administração Científica, a preocupaçãomaiordeTaylorera o aumento da produtividadeeda eficiência no campo operacional por meio da racionalização do trabalho operário. Para investigar essa possibilidade utilizou e aplicou métodos científicos.

A formulação desse pesquisador passou, mais tarde, a constituir a chamada Escola da Administração Científica. No centro dessa teoria estão as tarefas concebidas como atividades operacionais desenvolvidas pelos operários nas fábricas. Essa concepção veio revolucionar o pensamento administrativo. Taylor analisou profundamente o estudo dos tempos e dos movimentos para estabelecer padrões de atividades. Com base nessa análise, propôs o treinamento do operário para que ele desempenhasse seu trabalho, de forma regular e com maior proveito do tempo em função do aumento da produtividade. Procurou, então, adaptar as necessidades de patrão e empregados, assegurando a prosperidade entre eles.

$\mathrm{O}$ trabalho teórico de Taylor pode ser dividido em duas fases. $\mathrm{Na}$ primeira, realizou análises das atividades desenvolvidas individualmente pelo operário dentro da fábrica, esmiuçando todos os movimentos e processos. Seu objetivo era buscar o aperfeiçoamento para reduzir ao máximo esses movimentos e processos. Assim, chegou à especificação das técnicas de racionalização do trabalho. Ao analisar a prática dos operários, Taylor concluiu que o mais produtivo deles perde sua motivação de produção quando percebe que sua remuneração é a mesma de outro operário que, embora realize a mesma atividade, tem um ritmo de produção menor. Assim, deixa de produzir de acordo com sua capacidade máxima. Taylor então apontou a necessidade de se desenvolver novos mecanismos

Revista @rquivo Brasileiro de Educaçao, Belo Horizonte, vol.2, num.3. jan-jul. 2014. 
de remuneração para que o operário não deixasse de produzir de acordo com sua capacidade máxima. Assim, em seu livro Shop Management (TAYLOR apud CHIAVENATO, 2003, p. 55), ele descreveu suas conclusões:

- o objetivo da Administração é pagar salários melhores e reduzir custos unitários de produção;

- para realizar tal objetivo, a Administração deve aplicar métodos científicos de pesquisa e experimentos a fim de formular princípios e estabelecer processos padronizados que permitam o controle das operações fabris;

- os empregados devem ser cientificamente selecionados e colocados em seus postos com condições de trabalho adequadas para que as normas possam ser cumpridas;

- os empregados devem ser cientificamente treinados com vistas a aperfeiçoar suas aptidões e executar uma tarefa para que a produção normal seja cumprida;

- a administração precisa criar uma atmosfera íntima e cordial de cooperação entre os trabalhadores, para garantir a permanência desse ambiente psicológico.

Na segunda fase de seus estudos, Taylor obteve a conclusão de que "a racionalização do trabalho operário deveria ser acompanhada de uma estruturação geral para tornar coerente a aplicação dos seus princípios na empresa como um todo" (CHIAVENATO, 2003 p.55).

Como descrito, o meio para a racionalização do trabalho dos operários era o estudo de tempos e movimentos. Esse estudo indicou que movimentos inúteis deveriam ser eliminados e substituídos por outros eficazes. Assim, os empregados deveriam ser treinados na função específica de sua atividade, melhorando sua eficiência.

Dessa forma, a Administração Científica consolidou a divisão do trabalho, a especialização do operário, a definição e estabelecimento de cargos e tarefas, do incentivo salarial e de prêmios. $O$ entendimento era de que assim seria melhorada a condição física de trabalho e padronizados os métodoseequipamentos. Osprincípios básicosdaAdministraçãoCientífica de Taylor podem ser assim descritos, segundo Chiavenato (2003 p. 64):

- Princípio do planejamento: por meio dos métodos científicos

Revista @rquivo Brasileiro de Educaçao, Belo Horizonte, vol.2, num.3. jan-jul. 2014. 
O desenvolvimento histórico da administração e a gestão do ensino superior

substitui-se o improviso pela ciência, através do planejamento do método do trabalho.

- Princípio do preparo: norteia a escolha científica dos trabalhadores de acordo com suas capacidades/competências, preparando-os e treinando-os para produzir mais e melhor. Também as máquinas e equipamentos de produção devem ser preparados e deve ocorrer o arranjo físico e a disposição racional das ferramentas e materiais.

- Princípio de controle: norteia o comando das atividades de trabalho para se certificar de que está sendo realizado conforme as normas estabelecidas e o plano previsto.

- Princípio da execução: serve para distribuir as funções e as responsabilidades, a fim de que a execução do trabalho seja disciplinada.

À medida que Taylor estudava e desenvolvia a Administração Científica nos Estados Unidos, surgia, na França, a Teoria Clássica da Administração, criada por Henri Fayol (1841-1925). Nascido em Constantinopla, em uma estrutura familiar burguesa, ele foi educado no Liceu de Lion, na França. Graduando-se como engenheiro de minas, Fayol trabalhou em sua teoria que tinha como base e foco a estrutura da organização, cuja intenção era proporcionar aumento na eficiência da organização, por meio da definição dos vários níveis de responsabilidades. Assim como os princípios de Taylor, os preceitos gerais propostos por Fayol também estão presentes na prática administrativa contemporânea.

Até Fayol, o problema da prática da administração estava nas indústrias e usinas, uma vez que se preocupavam com a produtividade. O autor levou a administração do nível operacional da oficina para o nível da direção geral da empresa, considerando-se sua totalidade. A contribuição desse pesquisador para a administração consistiu em estabelecer que um processo administrativo complexo pode, e deve, ser separado em áreas interdependentes de responsabilidades ou de funções. Os princípios gerais da administração de Fayol foram:

- Divisão do trabalho: especialização do trabalho, tanto das tarefas quanto dos operários buscando-se maior competência.

- Autoridade e responsabilidade: definição da autoridade como "o direito de dar ordens e o poder para a exata obediência"; 
autoridade como responsabilidade com todo o corpo estrutural da empresa. A responsabilidade vem como resultado da autoridade, tendo como sentido a prestação de contas.

- Disciplina: consiste no fato de o funcionário direcionar seu comportamento de acordo com regras estabelecidas pela organização, esforço comum dos trabalhadores de maneira ordenada.

- Unidade de comando: o colaborador recebe ordens de um único chefe para evitar conflitos.

- Unidade de direção: a organização deve se mover em direção a um objetivo comum.

- Subordinação do interesse individual ao interesse geral: os interesses de uma pessoa não devem prevalecer sobre os interesses organizacionais em geral.

- Remuneração do pessoal: remuneração justa ao trabalho executado além de remuneração financeira, e recompensas não financeiras.

- Centralização: liderança natural, na qual a centralização era como "a diminuição da importância do papel do subordinado", enquanto a descentralização era a elevação dessa importância.

- Cadeia escalar: linha de autoridade, quantidade de autoridade correspondente à posição hierárquica.

- Ordem: alocação corretamente dos recursos, para se obter como resultado a diminuição de perdas de materiais, de tempo e otimização da mão de obra.

- Equidade: prática da justiça e do carinho dentro da organização em busca da fidelidade dos colaboradores.

- Estabilidade do pessoal no cargo: retenção dos trabalhadores mais produtivos deve ter alta prioridade da administração.

- Iniciativa: encorajamento da iniciativa do colaborador.

- Espírito de equipe: ênfase na harmonia e boa vontade geral entre os empregados, como forças da organização.

Assim, enquanto Taylor procurou resolver os problemas administrativos elevando-os do posto de trabalho do executor para o nível intermediário da gerência, Fayol enfocou os problemas de interesse da administração geral da empresa, qualquer que fosse sua natureza, tipo e finalidade. Taylor, para acelerar a produtividade da 
empresa industrial, começou pelo operário. Fayol começou pelos dirigentes. Conforme Silva (2001, p.153), "o fayolismo e o taylorismo se apresentam como duas soluções para um mesmo problema: o da força humana". As diferenças entre os dois sistemas são pequenas uma vez que Taylor interessava-se pelas condições técnicas do trabalho e Fayol pela administração da empresa, organizando o resultado de observações experimentais e psicológicas. Assim, Fayol completa o sistema de Taylor, validando e melhorando ambos os enfoques.

De acordo com Carvalho (2005), a administração, concebida como científica, corresponde à necessidade de racionalização do processo de trabalho, a profundado ediversificado pelo avanço da industrialização.Com a industrialização, a ação de produção adaptou-se a uma nova estrutura, ao empregar a ciência nas ações de trabalho e divisão de tarefas, afastando do trabalhador a totalidade do processo e separando, especialmente, o planejamento e a execução. Consolida-se, desse modo, a separação entre o trabalho intelectual e o manual, originando-se a figura do gerente e a organização racional dos processos produtivos. Conforme analisa Braverman (1987, p. 103), "todo possível trabalho cerebral deve ser banido da oficina e centrado no departamento de planejamento ou projeto".

Vale ressaltar que os princípios de Taylor e Fayol foram muito além do âmbito das fábricas invadindo e estruturando diversas dimensões da vida social e interferindo nas formas institucionais de gestão e organização, inclusive a escola. Como analisou Lima (1994), de modo generalizado, ocorreu nas escolas a "taylorização do trabalho educativo", uma vez que o método de gestão escolar, ao responder às demandas do mundo do trabalho e social, passou a considerar princípios comuns às empresas burocráticas, tais como:

- Rigidez das leis e dos regulamentos escritos: por esse princípio, a escola, assim como ocorria nas empresas, passou a ter seu regimento interno com a definição e exposição de leis e regulamentos, cabendo aos envolvidos, os agentes escolares, o seu cumprimento.

- Hierarquia da autoridade: assim como nas empresas, na escola também se verifica um sistema de hierarquia e autoridade, que vai desde o diretor responsável pela gestão até o corpo discente.

- Centralização do poder: na escola, instituiu-se a centralização do

Revista @rquivo Brasileiro de Educaçao, Belo Horizonte, vol.2, num.3. jan-jul. 2014. 
poder, conforme os níveis hierárquicos.

- Racionalização: a organização das ações dentro da escola passou a ser baseada em diagnósticos e princípios científicos, a fim de adaptar eficazmente os meios aos objetivos desejados.

- Especialização e divisão das funções entre planejamento e execução: esse princípio norteou a descrição dos cargos e funções dentro da escola e as respectivas responsabilidades de seus ocupantes.

Frigotto (1984) analisou a repercussão da administração científica na escola, em que a atividade do professor passou a ser a execução, na sala de aula, de planos previamente formulados, com conteúdos selecionados e organizados sequencialmente e critérios de avaliação pré-definidos. Com a divisão dos alunos em salas, instituiu-se a seriação do espaço, do tempo e dos saberes.

Como também mostrou Barroso (2000), a classe, antes um agrupamento de alunos, foi se transformando progressivamente num padrão de organização. Esse padrão serviu para departamentalizar a tarefa dos professores, divisão do seu percurso escolar e medição da progressão dos alunos.

Nessa relação que se vai formando entre administração científica e educação, a organização escolar e pedagógica passa a ser fundamentada nos princípios da divisão do trabalho desenvolvidos por Taylor e Fayol. Os currículos são ajustados por uma organização sistemática, rígida e fragmentada das áreas de conteúdo, tanto na seleção dos temas/assuntos quanto no sequenciamento dos mesmos, evidenciando-se cada vez mais a reprodução mecânica de atividades padronizadas visando chegar a uma igualdade de respostas e padronização dos procedimentos. Conforme Carvalho (2005), nesse sentido, o entendimento é de que todos os alunos passam pelos mesmos processos padronizados de ensino.

Em contraponto a esse modelo, ganha adeptos a administração burocrática, como se segue.

\subsection{A administração burocrática na organização escolar}

A corrente da administração científica passou a ser criticada 
principalmente por ser considerada mecanicista, limitando-se a questões ligadas ao cargo e à função do operário. Outra crítica que pesou sobre essa corrente refere-se à ausência de comprovação científica de seus postulados teóricos. Uma das correntes que criticou a administração científica foi a da administração burocrática, a qual surgiu com a finalidade de orientar o trabalho do administrador.

A palavra burocracia, idealizada por Jean Claude Marie Vicent, surge a partir do francês bureau (escritório) e do grego kratia (poder); aparece no século XVII, com o avanço dos organismos administrativos (CHIAVENATO, 2003). Mas, no final do século XIX, essa expressão passou a ser estudada no meio gerencial com maior profundidade, quando Talcott Parsons buscou, nas obras de Max Weber (1864-1920), a inspiração para a nova teoria da organização.

A administração burocrática, originada na Europa no início do século XX, surgiu como alternativa às teorias então conhecidas. Seu foco era a busca da racionalidade técnica, considerada essencial para projetar e construir um sistema administrativo baseado no estudo exato dos tipos de relacionamento humano necessários para expandir a produtividade.

Weber discutiu as relações entre mecanização e organização e interessou-se pelo processo de organização como parte do contexto social mais amplo. Para ele, as organizações assumem diferentes formas em função dos diferentes contextos e épocas. Por isso, compreendeu a forma burocrática de organização como a manifestação do processo mais amplo de racionalização na sociedade, nele destacando-se as relações entre meios e fins (MORGAN, 1996).

Weber (1987) descreveu a burocracia como um sistema de administração que aconselha a hierarquia, a disciplina rígida e a reverência à autoridade como "um tipo de dominação legal". Esse sistema também defende o acatamento de objetivos organizacionais e submete os funcionários a uma categoria inferior e desqualificada. Tais princípios administrativos reforçam a separação entre trabalho braçal e intelectual, coibindo a insubordinação da ordem. De acordo com Case (1996), essa análise negativa foi realizada à luz de grandes mudanças ambientais que exigiam das instituições em geral a tomada de decisão rápida e o gerenciamento transparente.

Chiavenato (2003) afirma que Weber foi o primeiro a analisar

Revista @rquivo Brasileiro de Educaçao, Belo Horizonte, vol.2, num.3. jan-jul. 2014. 
e sistematizar princípios administrativos com base em princípios da sociologia, da ciência, da política e do direito, realizando abstrações descritivas e sintetizando pontos comuns à maioria das empresas.

O modelo burocrático veio como uma proposta de estrutura administrativa para organizações complexas (FERREIRA; REIS; PEREIRA, 1997). O sistema burocrático definido por Weber é um sistema impessoal que funciona conforme regras e normas pré-estabelecidas, colocando em segundo plano as pessoas ou, sequer, considerando-as. Ao valorizar a competência profissional, Kwasnicka (1995) entende que a administração burocrática visa a que as pessoas desempenhem tarefas de acordo com padrões esperados. Case (1996), por sua vez, acrescenta que o objetivo da administração burocrática é simplificar a tarefa ao máximo para facilitar a substituição da pessoa ou o seu remanejamento no interior do sistema.

Já Chiavenato (2003) descreve os seguintes aspectos como característicos do modelo burocrático: estruturação hierárquica; racionalidade no papel desempenhado pelo indivíduo dentro da estrutura; existência de normas reguladoras das relações dentro das unidades produtivas. A divisão das atividades em áreas especializadas é alcançada pela definição clara e específica de deveres e responsabilidades de cada pessoa. A definição de cargos delimita áreas de competência que não podem ser desrespeitadas em nenhuma hipótese e, caso haja situações excepcionais, recorre-se ao órgão imediatamente superior. Dessa forma, estabelece-se a divisão do trabalho e a estruturação hierárquica de diferentes departamentos de forma racional e impessoal. Assim, a aceitação da autoridade não se dá no plano pessoal, ao contrário, deve ocorrer através do reconhecimento da racionalidade e da excelência nos serviços prestados. Ou seja, a autoridade deve ser vista como algo necessário no conjunto do sistema.

Nesse sentido, é necessário instituir um conjunto de normas e regras gerais e racionais de controle para a constância do funcionamento organizacional e o maior rendimento possível. Em razão das obrigações, responsabilidades e autoridade daqueles que exercem as atividades necessárias para o cargo, não raras vezes a pessoa fica esquecida e somente o regulamento é lembrado.

Combinando o enfoque sociológico com as ideias e princípios de Taylor, Weber (1987) estudou a organização como parte de um

Revista @rquivo Brasileiro de Educaçao, Belo Horizonte, vol.2, num.3. jan-jul. 2014. 
O desenvolvimento histórico da administração e a gestão do ensino superior

contexto social, influenciada pelas mudanças sociais, econômicas e religiosas da época, com a intenção de distinguir características comuns que aceitassem a tipologização. Ele identificou três tipos de sociedade, aos quais corresponderiam três tipos de autoridade:

- $\quad$ Autoridade tradicional: predomínio, na sociedade medieval (família, clã), das características patriarcais e patrimonialistas. A autoridade, nesse caso, provém da tradição e dos costumes, de maneira que as pessoas aceitam o poder de alguns em razão da crença no passado, na justiça e na virtude do modo tradicional de agir, bem como no status conferido pela herança ou sucessão.

- Autoridade carismática: predomínio das características místicas e personalísticas sendo a autoridade conferida pela capacidade de arrebatamento de uma personalidade sobre outras. O líder carismático é dotado de qualidades extraordinárias que causam devoção e legitimam sua autoridade.

- Autoridade racional, legal ou burocrática: predomínio das normas impessoais e da racionalidade na escolha dos meios e dos fins. A autoridade se legitima em função de que o grupo aceite o conjunto de preceitos e normas dos quais deriva o comando.

Weber (apud CHIAVENATO, 2003, p.259) relacionou a cada tipo de sociedade um tipo de autoridade existente, sendo que ambas têm como base o carisma, a tradição e a autoridade legal, racional ou burocrática. Nesse sentido, distinguiu o entendimento de autoridade e de poder. "Poder implica potencial para exercer influência sobre as outras pessoas" enquanto "autoridade significa a probabilidade de que um comando ou ordem específica seja obedecido".

As formulações de Weber que tipologizaram a sociedade contribuíram para a evolução dos modelos de gestão. A relação estabelecida entre tipo de autoridade e tipo de sociedade permitiu aos administradores maior compreensão do modelo de gestão a ser adotado para obter maior eficácia. Assim, as organizações passaram a se basear nas características do processo de gestão weberiano, entre as quais se destacam as seguintes:

- divisão do trabalho: atividades desmembradas em tarefas;

- $\quad$ hierarquia de autoridade: posições formando uma hierarquia estruturadora da organização;

Revista @rquivo Brasileiro de Educaçao, Belo Horizonte, vol.2, num.3. jan-jul. 2014. 


\section{Rafael Castro Rabelo}

- $\quad$ racionalidade: integrantes da organização são selecionados com base na qualificação técnica;

- regras e padrões: decisões gerenciais guiadas por regras, disciplina e controle, relacionados à conduta dos deveres oficiais;

- compromisso profissional: os colaboradores realizam suas atividades tendo salários fixos e não como donos dos negócios que administram;

- registros escritos: registro detalhado das transações da organização como base para a continuidade organizacional e com o propósito de alcançar uniformidade de ação;

- $\quad$ impessoalidade: as regras e os procedimentos são aplicados de modo uniforme e imparcial;

Os pressupostos weberianos apontam para a condução das organizações à máxima eficiência. Porém, ao longo da história, foi possível constatar sua disfuncionalidade. Os elementos humanos ocupantes de cargos operacionais, bem como gerenciais, geraram anomalias de funcionamento do modelo original, fazendo com que o termo burocracia adquirisse um sentido pejorativo e de ineficiência organizacional.

Remetendo-se ao campo da educação observa-se que, de um modo geral, a burocracia está bastante presente nas instituições de ensino, com um excesso de formalismo, normas e rotinas. As escolas são dotadas de normas e procedimentos, e os envolvidos no processo educacional devem cumpri-las em busca de maior eficiência.

Pode-se dizer que um dos traços reveladores da incorporação da burocracia na escola, em especial no ensino superior, é a prática de gestão assentada no excessivo valor a relatórios, a dados estatísticos, à avaliação quantitativa do desempenho dos alunos, à comparação do desempenho dos alunos perante as demais escolas, à quantidade de alunos aprovados no vestibular, e assim por diante. A valorização dos registros e dados é um mecanismo básico para evidenciar o desempenho quantitativo escolar assim como sua eficiência, auxiliando, por exemplo, na captação de maior número de alunos em um meio social assentado na competitividade.

Do professor, espera-se que cumpra as normas e regras impostas pela instituição de ensino. As práticas pedagógicas dos docentes sofrem interferência, não no sentido pedagógico, mas sim no sentido burocrático,

Revista @rquivo Brasileiro de Educaçao, Belo Horizonte, vol.2, num.3. jan-jul. 2014. 
uma vez que o docente deve seguir uma rotina de trabalho, como: utilizar o documento diário para realizar a chamada dos alunos, livros adotados pela escola, horários estabelecidos, estilos de aula, relatórios para serem apresentados nos conselhos de classe etc. Todos esses aspectos acabam sendo mais valorizados, ficando a dimensão pedagógica em segundo plano, quando não é anulada.

Nesse sentido, as disfunções mais importantes decorrentes da aplicação da teoria da administração burocrática nas escolas são: excesso de formalismo, exagerado apego aos instrumentos normativos, rigidez comportamental, conformismo e estagnação funcional. A realidade comprova as influências advindas da administração burocrática com a ampla valorização de regras e normas. A escola, com esse modelo de gestão, passou a se preocupar em cumprir ritos burocráticos, como reuniões constantes. Ainda que seja importante para ela se valer de instrumentos normativos e formais, o maior risco é que a ênfase exagerada às regras e aos procedimentos possa torná-los mais importantes por si mesmos do que como meios para melhorar o alcance dos objetivos pedagógicos da organização escolar, bem como a relevância das relações humanas.

\subsection{Administração das relações humanas}

A administração das relações humanas é uma vertente teórica que se iniciou nos Estados Unidos, na primeira metade do século XX. Seu caráter de oposição à escola clássica decorre da crítica feita às teorias da época, apontando a insuficiência de seu foco na tarefa (Taylor), na estrutura, (Fayol) e na burocracia e ou autoridade (Weber). A vertente teórica da administração das relações humanas destaca a necessidade de humanizar e democratizar a administração a fim de superar os princípios rígidos e mecanicistas da teoria clássica. Essa posição argumenta que o ser humano, inserido em seu contexto social, deve ser o principal enfoque da organização em suas atividades administrativas.

Essa escola teve como base e princípios os estudos de Mayo (1880-1949). Silva (2001) descreve que os experimentos realizados por Mayo e conhecidos como experiência de Hawthorne ${ }^{3}$ demonstraram
3 Elton Mayo (1880-1949) nasceu na Austrália e foi o principal protagonista da Escola das Relações Humanas. Responsável pela experiência de Hawthorne realizou quatro pesquisas voltadas para o comportamento humano no trabalho. O primeiro estudo foi realizado na Filadélfia em uma fábrica de tecidos no qual Mayo concluiu que os funcionários se mostravam tristes e deprimidos por consequência da fadiga. Estabeleceu, então, a necessidade períodos de descanso no decorrer do dia de trabalho. O segundo estudo aconteceu na fábrica de Hawthorne e tratou do relacionamento entre as pessoas no trabalho. Ele constatou que, em uma relação harmoniosa, o colaborador é capaz de aumentar significativamente sua produção. No terceiro estudo, que se realizou em três indústrias metalúrgicas, constatou-se que o colaborador, ao receber treinamento fundamentado na paciência, atenção e no controle emocional, valorizava sua reputação reduzindo o alto índice de absenteísmo. O quarto e último estudo foi realizado em uma fábrica de aviões na qual os líderes incitavam a solidariedade com os demais colaboradores, despertando o espírito de equipe.

Revista @rquivo Brasileiro de Educaçao, Belo Horizonte, vol.2, num.3. jan-jul. 2014. 
que as atitudes e necessidades dos trabalhadores afetam sua motivação e seu comportamento. Revelaram também que há uma relação enormemente complexa entre a produção e a eficiência.

Assim, os estudos de Mayo ampliaram o objeto da administração, ao atingir seus objetivos de "conciliar" e "harmonizar" os conflitos inseridos entre organização e colaborador, pois cada qual possui objetivos específicos distintos. O que se buscou com esse estudo foi a harmonia, o controle e a satisfação entre os envolvidos na organização, ou seja, a correlação da atividade prática, da produtividade e das condições específicas de trabalho a uma abordagem social da empresa, conferindo relevância ao ser humano e suas motivações.

Do ponto de vista de Bernardi (2007), essa escola das relações humanas é um modelo que tem como base a organização informal e o comportamento grupal, dirigindo-se ao comportamento do ser humano e às suas relações informais na organização, inserindo-se os valores sociais e grupais para atingir objetivos organizacionais. Porém, é criticada por seus opositores, os quais consideram que o problema da empresa é a lucratividade e que aspectos sociais não são problemas empresariais. Entendem que a preocupação social presente dentro da empresa aumenta os custos reduzindo sua lucratividade. Isso tornaria irreal e impraticável a abordagem das relações humanas. Essa corrente ressalta, então, a tendência comportamental discutida a seguir.

\subsection{O enfoque comportamental na administração}

Este enfoque, ao contrário da escola das relações humanas e, ao mesmo tempo, complementando-a, crê que a atividade prática do trabalho e a produção estejam interligadas às condições de trabalho, além da abordagem social da empresa. Todavia, considera falsa a crença de que somente com a satisfação do trabalho se consegue chegar à eficiência e à produtividade.

Essa escola critica tanto a teoria clássica por seus princípios rígidos como a escola burocrática por seu "modelo máquina". Segundo Silva (2001), a teoria comportamental centrou-se no valor do comportamento do indivíduo.

Assim, a teoria comportamental da administração (ou teoria 
O desenvolvimento histórico da administração e a gestão do ensino superior

behaviorista da administração) fundamentou-se no comportamento individual das pessoas, estudando a motivação humana, definindo estilos de administração e caracterizando as organizações como sistemas sociais cooperativos e de decisões. Essa abordagem foi influenciada sobremaneira pelas ciências comportamentais, mais especificamente pela psicologia organizacional. Como lembra Chiavenato (2003), o behaviorismo, fundado por Watson, em oposição ao subjetivismo predominante na psicologia de sua época, introduziu na psicologia a objetividade científica, baseada na comprovação experimental. 0 behaviorismo centra-se no indivíduo e estuda seu comportamento (aprendizagem, estímulo e reações de resposta, hábitos etc.), não por meio de conceitos subjetivos, mas por meio de manifestações verificadas em laboratório experimental.

O behaviorismo trouxe sentido e rumo às teorias da administração, tendo o comportamento do indivíduo como algo valioso, reduzindo-se cada vez mais as regras e normas descritivas das teorias de até então. Teve seu início com Hebert Alexander Simon, dando continuidade com Chester Barnad, Douglas McGregor, Rensis Linkert, Chris Argyris. No campo da motivação humana podem ser citados Abraham Maslow, Frederick Herzberg e David McClelland (CHIAVENATO, 2003).

Dopontodevista daabordagemcomportamentalista, compreender o comportamento organizacional é extremamente importante. Para isso, faz-se necessário estudar o comportamento individual das pessoas, uma vez que as organizações são compostas por elas. Partindo desse pressuposto, explicar as formas de comportamento é importante para entender a motivação humana. Os autores behavioristas defendem que o administrador deve conhecer as necessidades humanas para melhor compreender o desempenho das pessoas e utilizar a motivação humana para melhorar a qualidade de vida dentro das organizações (CHIAVENATO, 2003).

Maslow (1908-1970), um dos maiores estudiosos da motivação humana, criou a teoria da motivação na qual demonstra as necessidades humanas sistematizadas em níveis hierárquicos de importância e influência. Um indivíduo estará motivado e conseguirá passar de um nível para outro mais elevado quando conseguir suprir sua necessidade ou nível atual. Ou seja, o ser humano tende a realizar suas necessidades

Revista @rquivo Brasileiro de Educaçao, Belo Horizonte, vol.2, num.3. jan-jul. 2014. 
primárias (mais baixas na pirâmide), antes de buscar resolver aquelas de nível mais elevado.

Contudo, nem todas as pessoas conseguem chegar ao topo da pirâmide de necessidades. Assim, quando as mais baixas estão razoavelmente satisfeitas, as localizadas nos níveis mais elevados começam a dominar o comportamento. Entretanto, quando a necessidade de nível inferior deixa de ser atendida, ela volta a predominar no comportamento, gerando tensão no organismo. Cada indivíduo possui sempre mais de uma motivação e toda necessidade está ligada ao estado de satisfação ou insatisfação de outras necessidades. Por isso, seu efeito sobre o organismo é sempre global e nunca de forma isolada. Qualquer comportamento motivado é um canal por meio do qual, várias necessidades fundamentais podem ser expressas ou satisfeitas conjuntamente. Qualquer possibilidade e/ou frustração de determinadas necessidades passa a ser uma ameaça psicológica. Essa ameaça, por sua vez, produz as reações gerais de emergência no comportamento humano.

Acerca dessa teoria, Chiavenato (2003) refere que inúmeros trabalhos não conseguiram obter comprovação científica, sendo que alguns deles chegaram até a invalidá-la. No entanto, o autor considera que a teoria de Maslow é suficientemente bem estruturada para oferecer um esquema orientador e útil para a atuação do administrador.

Além de Maslow, Herzberg focou o interesse na compreensão da motivação para explicar o comportamento humano, porém encaminhou seu estudo para a motivação em situação de trabalho. Sua conclusão foi a de que o comportamento das pessoas é controlado por dois fatores: os insatisfatores (que causam a insatisfação/higiênicos) e os satisfatores (que causam a satisfação/motivacionais). A ausência de insatisfatores não basta; os satisfatores devem estar claramente presentes para motivar os colaboradores a desempenhar bem suas atividades na empresa.

Essa teoria classifica as necessidades em duas modalidades: as de satisfação no trabalho e as de motivação. A satisfação no trabalho relaciona-se com as condições e circunstâncias em que o trabalho é desenvolvido, supervisão, relações interpessoais, condições físicas, salários, benefícios etc. Já as necessidades de motivação estão diretamente 
O desenvolvimento histórico da administração e a gestão do ensino superior

relacionadas com a tarefa e o trabalho, o desenvolvimento do potencial humano e a realização de aspirações individuais, liberdade, criatividade e inovação. Para Aguiar (1992), a teoria de Herzberg transforma o indivíduo num meio para se atingir os fins da organização.

Barnad, pensador behaviorista, apresentou a teoria da cooperação que estuda a autoridade e a liderança para interpretar as organizações. Segundo ele (1979), as pessoas não desenvolvem suas atividades organizacionais isoladamente, mas em interação com outras pessoas para atingirem resultados. Por meio dessa cooperação, surgem as organizações. Nesse contexto, os administradores devem ser capazes de criar e manter um sistema de esforços cooperativos dentro da organização, ou seja, devem criar condições que incentivem a coordenação de atividades organizadas.

Ainda na abordagem comportamentalista, March e Simon criaram a teoria das decisões, considerando que a organização é um sistema de atividades que exige continuamente inúmeras decisões. Assim, as pessoas participam de forma ativa, racional e conscientemente, tomando decisões individuais em relação ao comportamento. Nesse sentido, a organização se apresenta carregada de decisões e ações. Para os autores, os empregados tomam duas decisões: a primeira é a de "fazer parte da organização ou deixar a organização"; a segunda é de "produzir ou recusar-se a produzir na escala exigida pela hierarquia da organização" (MARCH; SIMON apud MA 2004, p. 50).

A abordagem comportamentalista repercute na organização escolar implicando um modelo de escola que passa a se organizar com um novo perfil de gestor. O gestor deve ser um líder educacional, cabendo-lhe despertar o potencial de cada colaborador da instituição escolar, transformando a escola em oficina de trabalho onde todos cooperam, aprendem e ensinam constantemente.

O gestor da escola que se fundamenta nessa teoria preocupase com as questões da motivação humana e, portanto, deve conhecer os mecanismos motivacionais para que possa dirigir adequadamente a escola por meio das motivações das pessoas, que são o organismo vivo da instituição. Os colaboradores são tomadores de decisões a todo instante, em especial os professores que, ao desenvolverem suas práticas pedagógicas em salas de aula com base nas informações que recebem

Revista @rquivo Brasileiro de Educaçao, Belo Horizonte, vol.2, num.3. jan-jul. 2014. 
constantemente de seu ambiente, processando-as de acordo com suas convicções e assumem atitudes e opiniões em circunstâncias, uma vez que a instituição é vista como um sistema de decisões. Entretanto, surge nova abordagem na área da administração, como procuro analisar no item a seguir.

\section{A administração estruturalista}

Até a incorporação do behaviorismo em suas teorias, a administração apresentava um modelo de gestão, cujo caráter era complemento e incremento, quando comparado aos modelos anteriores. Bernardi (2007) afirma que, de maneira geral, os pressupostos centrais envolvidos pelos paradigmas aceitos com a divisão do trabalho, o reducionismo e o mecanicismo permaneciam e eram reincorporados ao desenvolvimento das teorias administrativas até então estudadas.

Nesse sentido, a administração científica foi um marco fundamental de transição da escola clássica para a escola das relações humanas e, consequentemente, as pesquisas de Mayo tiveram o papel de promover essa mudança, chegando ao estruturalismo que passou a ser uma nova perspectiva na área da administração.

Segundo Silva (2001), novas projeções foram lançadas às organizações com o trabalho do sociólogo Etzioni. Ao julgar insatisfatórias as correntes até então conhecidas, ele trabalhou uma síntese denominando-a de estruturalismo. Esse estudo foi realizado de forma ampla e integral, considerando-se todos os fatores que pudessem interferir de forma interna e externa nas organizações, comparando-os e analisando-os de maneira global.

Essa abordagem percebe e reconhece que os fenômenos referentes à organização se interligam, interpenetram e, consequentemente, interagem de modo que qualquer alteração ou interferência em uma parte da organização afetará de algum modo, suas demais partes comprometendo seu funcionamento de forma global. Essa é a primeira abordagem que enfoca a organização como sistema aberto, ou seja, que valoriza a interação entre instituições humanas e o ambiente em que elas estão inseridas. Bernardi assim define a estrutura:

Revista @rquivo Brasileiro de Educaçao, Belo Horizonte, vol.2, num.3. jan-jul. 2014. 
O desenvolvimento histórico da administração e a gestão do ensino superior

[...] um todo que se compõe de elementos que o formam,
uma organização produtiva e social e uma inter-relação
entre os elementos, desenhando-se, a partir disso, os
pressupostos do Estruturalismo. Os estudos desta escola
concentram-senaracionalidadecomoum equilíbrio entre
meios e fins, no poder da burocracia na organização e na
impessoalidade organizacional (BERNARDI, 2007. p.30).

Os estudos de Etzioni contribuíram para desenvolver uma "tipologia de organização", examinando de que maneira o envolvimento individual com uma determinada empresa e a relação de poder nela estabelecida se relacionam para explicitar o consentimento do poder entre os envolvidos: "o consentimento está relacionado ao significado de poder e à orientação do indivíduo" (SILVA, 2001, p. 284).

Etzioni caracterizou três formas de poder como ferramentas da atividade prática de administração:

1. o poder coercitivo: focado nas sanções físicas;

2. o poder remunerativo: focado nos recursos econômicos;

3. o poder normativo: focado nas recompensas simbólicas.

De acordo com Bernardi (2007), essas ferramentas de controle se fazem importantes para que a organização possa apresentar e fixar junto aos indivíduos o comportamento administrativo necessário. Assim, essa teoria fornece um modelo de empresa como uma estrutura em interrelação com o ambiente em que atua, onde a possível relação de harmonia natural, inserida na escola clássica e mantida nas relações humanas, é relativa, pois há poder, burocracia e conflitos. Nessa evolução de estudos acerca da gestão mais uma corrente ganha corpo, como abordo a seguir, de forma resumida.

\subsection{A administração sistêmica}

A Teoria Geral de Sistemas (TGS) foi sustentada pelos estudos de Ludwig Von Bertalanffy, que a denominou de teoria de sistemas abertos. A TGS busca explicar que um sistema se baseia numa consciência de inter-relação e interdependência entre o ambiente interno e externo, ou

Revista @rquivo Brasileiro de Educaçao, Belo Horizonte, vol.2, num.3. jan-jul. 2014. 
seja, uma organização não é um conjunto de elementos separados, mas sim um sistema específico e organizado de forma global.

Segundo Silva (2001, p.352), na perspectiva da TGS, um sistema é concebido como "um conjunto de elementos interativos e relacionados cada um ao seu ambiente de modo a formar um todo". Portanto, uma organização pode e deve ser considerada um sistema organizacional. As organizações de negócios são sistemas constituídos por indivíduos em constante interação com o ambiente, consumidores ou clientes externos, concorrentes, colaboradores, fornecedores, entre outras entidades envolvidas. Esses sistemas se inter-relacionam, buscando-se um trabalho conjunto para atingir determinados objetivos. Desse modo, tanto as organizações como as pessoas ou grupos envolvidos têm seus objetivos específicos a serem atingidos.

O objetivo dessa teoria aplicada às organizações é o de criar um ambiente específico para auxiliar os gestores nas suas tomadas de decisões.

Daniel Katz e Robert Kahn, pesquisadores atuantes na Universidade de Michigan, acreditaram e defenderam a Teoria dos Sistemas Abertos e a eficácia de sua aplicação nas empresas. Defenderam também que para a sobrevivência de uma organização, ela deve manter constantes interações com o ambiente no qual está inserida.

A TGS ofereceu uma perspectiva teórica para analisar, avaliar e transformar as organizações quanto aos seus modelos de gestão, com ênfase na necessidade de interação dos subsistemas, contrapondo-se ao entendimento da organização como sistema fechado e burocrático e trazendo o entendimento da organização como sistema aberto, interativo e eficaz. As IES, por sua vez, não ficam imunes a essas influências, é o que procuro discutir na sequência.

\subsection{A influência da administração na gestão do ensino superior público}

Nesta parte do texto, busco fazer uma relação entre a evolução da

Revista @rquivo Brasileiro de Educaçao, Belo Horizonte, vol.2, num.3. jan-jul. 2014. 
O desenvolvimento histórico da administração e a gestão do ensino superior

administração e seus reflexos no ensino superior brasileiro. Tendo como ponto de corte a Reforma Universitária de 1968, utilizo como referência autores como Luiz Antônio Cunha, Ana Maria Migott, Nilson Nobuaki Yamauti, Vera Vergara Esteves, Hélgio Trindade, entre outros, que se dedicaram a análises acerca da gestão na universidade.

A universidade é uma organização voltada ao conhecimento que constitui sua verdadeira razão de existir. De acordo com Chauí (2001), a universidade tem como proposta e razão ser "uma instituição social", caracterizada por ação e prática social. A partir da análise da organização universitária, é importante pensar em um conjunto de princípios de organização e gestão para a universidade, adequados à sua realidade atual e aos desafios que enfrenta. Tais princípios permitiriam a estruturação de um modelo organizacional para a universidade, tendo por suporte um conjunto de procedimentos de gestão.

Tomando-se por base a evolução da administração e a reforma universitária de 1968, e com o apoio teórico de Cunha (1999) e Yamauti (2004), pude compreender claramente que os estilos de gestão, utilizados até hoje nas universidades, são estilos influenciados pelas teorias de Taylor (racionalização do trabalho), Fayol (estrutura organizacional) e Weber (estilo burocrático de gestão).

A presença da administração científica formulada por Taylor fica bem clara e encontra-se expressa, por exemplo, na reforma universitária de 1968, em duas diretrizes: 1) eliminação da duplicação de meios para fins idênticos; 2) separação entre as atividades de concepção e execução.

SegundoCunha (1999), essas duas orientações foram internalizadas na estrutura e funcionamento das instituições universitárias brasileiras, principalmente na rede federal. As universidades federais nos anos 60 encontravam-se em uma situação caótica e suas estruturas físicas apresentavam-se com capacidade máxima aproveitada, assim como o quadro de colaboradores nas áreas de ensino e administração. O regime de cátedras era visto como o principal responsável pela situação. Em se tratando dos currículos, o curso era o alicerce das universidades, quanto à sua organização. Este, por sua vez, era separado em matérias, correspondendo cada qual a uma cátedra. Esse fato causava um transtorno enorme no sentido de que era necessário modificar e alterar o número e a composição das cátedras, o que interferia no quadro dos

Revista @rquivo Brasileiro de Educaçao, Belo Horizonte, vol.2, num.3. jan-jul. 2014. 
agentes escolares e nas estruturas complementares necessárias para o funcionamento do curso, como: laboratórios, oficinas, bibliotecas, entre outras.

Nesse sentido, a reforma universitária veio com o propósito de solucionar um grave problema de saturação nas universidades federais, uma vez que o sistema de cátedras vigente era apontado como o grande responsável por essa saturação. O que se buscava com a reforma era a condição ideal de organização do ensino superior em suas funções de ensino, pesquisa e extensão. Aspectos da reforma foram descritos por Cunha da seguinte maneira:

O regime de cátedras foi extinto pela lei 5.540, de 11 agosto de 1968, substituído pelo regime departamental e pela divisão dos cursos de graduação entre o ciclo básico e o ciclo profissional. Os professores das disciplinas idênticas ou semelhantes foram agrupados no mesmo departamento. A departamentalização implicou, também, a criação de uma nova instância na organização das universidades - a coordenação e o colegiado de curso. Este seria formado de representantes dos departamentos cujas disciplinas colaboram, em diferentes medidas, em cada curso de graduação. Complementando a departamentalização e a divisão dos cursos de graduação, o regime de matrícula por disciplina veio a compor uma tríade que levaria à pretendida minimização do custo de matrícula adicional (CUNHA, 1999, p. 92).

Com a reforma universitária, a condição de organização ideal, com relação ao ensino, à pesquisa e à extensão, conforma-se às formulações de Taylor e de Fayol. Na abordagem científica defendida por esses autores, ocorre a organização racional do trabalho e a estrutura organizacional com a divisão do trabalho, a departamentalização, a especialização, o estabelecimento de cargos e tarefas, a padronização de métodos, a hierarquia da autoridade, a centralização do poder, etc.

O modelo de gestão inserido na "nova estrutura organizacional", a partir da reforma adotada nas universidades brasileiras em 1968, foi o da gestão burocrática desenvolvida por Weber. Os órgãos responsáveis pelas universidades desenvolveram e implantaram normas e regras a serem estabelecidas por meio de uma estrutura hierárquica de controle. Como ressalta Yamauti (2004), nesse modelo, os superiores hierárquicos, em tese, trabalham com instrumentos de coerção para garantir que seus subordinados obedeçam às normas estabelecidas.

Nesse sentido, os colaboradores envolvidos nas Instituições de 
Ensino Superior, desempenham suas atividades e funções em razão da coerção, visto que as pessoas se tornam simples cumpridoras de ordens. Isso acarreta conformismo, desmotivação, falta de participação e envolvimento de um real compromisso com os fins da instituição.

De modo geral, as universidades no Brasil, especialmente as públicas, adotaram esse estilo de gestão em que as normas e regras são criadas, desenvolvidas e impostas pelo governo ou órgão responsável.

Nas IES privadas também é predominante esse estilo de gestão burocrático, que necessita atender aos anseios do mercado capitalista uma vez que vivemos num mundo, cuja característica básica é o processo de mudanças rápidas, imprevistas, turbulentas e inesperadas. Em um mundo no qual o capitalismo se amplia e se aprofunda, a informação e a competitividade são ferramentas imprescindíveis para as organizações.

A competitividade/concorrência são variáveis incontroláveis no ambiente em que as organizações atuam, por isso, passou a existir uma valorização maior do consumidor. O cliente passou a dominar o cenário da comercialização como um dos caminhos para a obtenção de melhores resultados. Em se tratando de concorrência, a Instituição de Ensino Superior (IES) do setor privado, como organização com fins lucrativos, não fica atrás das organizações de outras áreas com finalidades distintas da educação e do ensino. A expansão do ensino superior à custa do setor privado está resultando no aparecimento de inúmeras instituições que oferecem diversos cursos, sendo pouca a variação no valor das mensalidades de uma para outra. Consequentemente acirra-se a competição e a busca de meios de permanência nesse "mercado".

Perante essa realidade, as IES privadas começaram a fechar mais seu foco, tendo como principal "missão" a lucratividade na venda de serviços educacionais. Este foco, no entanto, nem sempre inclui a qualidade do ensino, da formação e dos cursos, priorizando, assim, o mercado capitalista. Na perspectiva de reter o aluno considerado como cliente, utiliza-se de uma prática de gestão burocrática, sem participação da sua equipe de trabalho, refletindo nas práticas pedagógicas do docente.

Aos envolvidos nas IES públicas e privadas - docentes, discentes e técnico-administrativos - cabe cumprir a um regimento imposto de forma coercitiva. Assim, são excluídos aspectos importantes das

Revista @rquivo Brasileiro de Educaçao, Belo Horizonte, vol.2, num.3. jan-jul. 2014. 
relações humanas como: amor, liberdade, autonomia, prazer de exercer o papel de sujeito de seu próprio destino, que são fundamentais para uma transformação social que a universidade deveria proporcionar à sociedade em geral, com base no conhecimento. Entretanto, subsidiado pelos estudos, constato que o papel dos sujeitos acaba se restringindo a cumprir regras, normas e procedimentos para a transmissão de conteúdos aos alunos.

\title{
Considerações finais
}

Este estudo representa um trabalho humilde diante da complexidade do tema e da riqueza com que pode ser analisado. Caracteriza-se apenas como uma tentativa de descrever a gênese da administração como campo de conhecimento e de práticas voltadas para as organizações, em especial, as de ensino. Por se tratar da interpretação teorias da administração, limitei-me às minhas experiências enquanto pesquisador iniciante, não só no tema, como também na prática da pesquisa. Ainda assim, acredito que este estudo deva ser considerado por seu caráter inovador no campo da Gestão do Ensino Superior e por apresentar alguns pontos de reflexão que poderão servir para futuras análises, mais aprofundadas e consistentes.

\begin{abstract}
This article assumes that human work that takes place in an educational institution of higher education has the management as one of its essential elements. The question that guided the research was: what is the influence of different management schools in the manage way deployed in public and private Brazilian higher education? The relevance of investigating this issue is evident in the contribution it brings to understanding the management at the university today, its elements and its contradictions. We opted for the bibliographic research. The main objective was to describe the administration genesis as a field of knowledge and practices for organizations. For this purpose, we selected, among others, works of two authors in the field of business administration in Brazil: Idalberto Chiavenato and Reinaldo Oliveira da Silva. First, we try to show the development of management in society, particularly in organizations, to then consider the importance of this administration in education, particularly in the university management.
\end{abstract}

Keywords: |University management; historical administration development; bureaucratic management

Revista @rquivo Brasileiro de Educaçao, Belo Horizonte, vol.2, num.3. jan-jul. 2014. 
desenvolvimento histórico da administração e a gestão do ensino superior

\section{Referências}

AGUIAR, Maria Aparecida F. de. Psicologia aplicada à administração. São Paulo: Excellus e Consultoria, 1992.

BARNARD, Chester I. As funções do Executivo. São Paulo: Atlas, 1979.

BARROSO, J. O reforço da autonomia das escolas e a flexibilização da gestão em Portugal. In: FERREIRA, Naura S.C (org.). Gestão democrática da educação: atuais tendências, novos desafios. 2. ed. São Paulo: Cortez, 2000, p.11-32.

BERNARDI, Luiz Antônio. Manual de empreendedorismo e gestão: fundamentos, estratégias e dinâmicas. 1. ed. 5. reimpr. São Paulo: Atlas, 2007.

BRAVERMAN, H. Trabalho e capital monopolista. 3 ed. Rio de Janeiro: JC Editora, 1987.

CARVALHO, E.J.G. Autonomia da gestão escolar: democratização e privatização, duas faces de uma mesma moeda. Piracicaba Tese (Doutorado), 2005, 235f., Programa de Pós-Graduação em Educação. Universidade Metodista de Piracicaba. Piracicaba.

CASE, J. Open book management: gerenciamento transparente. Trad. Bazan Tecnologia e Linguística. Rio de Janeiro: Ediouro, 1996.

CHAUÍ, Marilena. Escritos sobre a universidade. São Paulo: UNESP, 2001.

CHIAVENATO, Idalberto. Introdução à teoria geral da administração. 7. ed. Rio de Janeiro: Campus, 2003.

CUNHA, L.A. A universidade temporã. $2^{\mathrm{a}}$ ed. Rio de Janeiro: Francisco Alves, 1986.

A universidade crítica. $2^{\mathrm{a}}$ ed. Rio de Janeiro: Francisco Alves, 1989.

A universidade reformanda. Rio de Janeiro: Francisco Alves, 1988.

A universidade brasileira entre o taylorismo e a anarquia. Revista

Brasileira de Educação, Caxambu, n.10.p.90-96, jan./abr.1999.

FERREIRA, A.A.; REIS, A. C. F; FERREIRA, M.I. Gestão empresarial: de Taylor aos nossos dias. Evolução e tendências da moderna administração de empresas.

São Paulo: Pioneira,1997.

FRIGOTTO, G. A produtividade da escola improdutiva. São Paulo: Editora Cortez: Autores Associados, 1984.

KWASNICKA, E.L. Teoria geral da administração: uma síntese. 2. ed. São Paulo: Atlas, 1995.

LIMA, L. C. Modernização, racionalização e optimização. Perspectivas neotaylorianas na organização da administração escolar. Cadernos de

Ciências Sociais. Braga, Centro de Estudos em Educação e Psicologia, 
Instituto de Educação e Psicologia-IEP da Universidade de Minho, n. 14. p.119-139. Jan.1994.

MA, Janaina. A natureza do conhecimento administrativo: uma busca pelo seu objeto. Dissertação de Mestrado, Salvador: UFBA, 2004.

MACHADO, Luis Eduardo. Gestão Estratégica para Instituições de Ensino Superior Privadas. Rio de Janeiro: FGV, 2008.

MORGAN, G. Imagens da organização. Trad. C. W.Bergamini, R. Cola. São Paulo: Atlas, 1996.

SILVA, Reinaldo Oliveira. Teorias da Administração. São Paulo: Pioneira Thompson Learning, 2001.

VIEIRA, Eurípedes F.; VIEIRA, Marcelo M. F. Funcionalidade burocrática nas universidades federais: conflito em tempos de mudança. Revista de Administração Contemporânea. Vol. 8 n. 2. Curitiba Abr/Jun. 2004.

WANDERLEY, L.E.W. Criação de novas universidades: um processo à brasileira. São Paulo, n.8.p.86-91, mai./ago.1998.

WEBER, M. Conceitos básicos de sociologia. Trad. G. G. Delaunay, R. E. F. Frias. São Paulo: Moraes, 1987.

YAMAUTI, Nilson Nobuaki. É possível transformar o modelo burocrático de gestão da universidade?. Revista Espaço Acadêmico. n. 42.nov. 2004. 